\title{
Different Storing and Processing Conditions of Human Lymphocytes do not Alter P-Glycoprotein Rhodamine 123 Efflux
}

Gemma Chiva-Blanch*1,2 ${ }^{1,}$ Pepita Giménez-Bonafe*², Inés Llaudó ${ }^{1}$, Joan Torras ${ }^{1}$, Josep M Cruzado ${ }^{1}$, Jordi Petriz ${ }^{3}$, Esther Castaño ${ }^{4}$, Marcel·la Franquesa ${ }^{1}$, Immaculada Herrero-Fresneda ${ }^{1}$, Avelina Tortosa ${ }^{5}$, Inés Rama ${ }^{1}$, Oriol Bestard $^{1}$, Josep M. Grinyó ${ }^{1}$ and Núria Lloberas ${ }^{1 *}$

\begin{abstract}
${ }^{1}$ Nephrology Department, IDIBELL-Hospital Universitari Bellvitge, L'Hospitalet de Llobregat, Spain. ${ }^{2}$ Departament de Ciències Fisiològiques II, Facultat de Medicina, IDIBELL, University of Barcelona, Spain. ${ }^{3}$ Institut de Recerca de l'Hospital Universitari Vall d'Hebron, Barcelona, Spain. ${ }^{4}$ Serveis Cièntifico-tècnics de la Universitat de Barcelona, Unitat de Biologia-Bellvitge. ${ }^{5}$ School of Nursing, Department of Basic Nursing, IDIBELL-Barcelona University, L'Hospitalet de Llobregat, Spain.
\end{abstract}

Received, May 15, 2009; Revised, September 22, 2009, Accepted, November 25, 2009, Published, November $25,2009$.

\begin{abstract}
P-glycoprotein (Pgp), a protein codified by Multi Drug Resistance (MDR1) gene, has a detoxifying function and might influence the toxicity and pharmacokinetics and pharmacodynamics of drugs. Sampling strategies to improve Pgp studies could be useful to optimize the sensitivity and the reproducibility of efflux assays. This study aimed to compare Pgp expression and efflux activity by measuring Rhodamine123 (Rh123) retention in lymphocytes stored under different conditions, in order to evaluate the potential utility of any of the storing conditions in Pgp functionality. Our results show no change in protein expression of Pgp by confocal studies and Western blotting, nor changes at the mRNA level (qRT-PCR). No differences in Rh123 efflux by Pgp activity assays were found between fresh and frozen lymphocytes after 24 hours of blood extraction, using either of the two Pgp specific inhibitors (VP and PSC833). Different working conditions in the 24 hours post blood extraction do not affect Rh123 efflux. These results allow standardization of Pgp activity measurement in different individuals with different timing of blood sampling and in different geographic areas.
\end{abstract}

\section{INTRODUCTION}

P-glycoprotein (Pgp) is a multridug transporter that belongs to the ATP-Binding Cassette (ABC) family, and it is the product of the Multidrug Resistance-1 (MDR-1) gene. Pgp acts as a drug efflux pump extruding a range of different hydrophobic drugs from cells, contributing to drug disposition in humans and reducing the bioavailability of many orally administered medications. Pgp confers the multidrug resistant phenotype by maintaining reduced intracellular concentrations of anticancer drugs by virtue of its ability to act as a primary active transporter (1-3). As well, Pgp plays a role in the cells of the immune system, particularly in dendritic cell maturation and function $(4,5)$. This multifaceted involvement in drug disposition, cancer drug resistance and regulation of the immune response makes Pgp an attractive target to deepen the optimization of different strategies and to foster a better understanding of its function in cells and tissues.

Pgp works as a transporter molecule pumping a wide variety of endogenous substances and drugs from the cytoplasm to the exterior of the cell (6). Many widely used clinical agents are substrates, inhibitors or inducers of Pgp, including immunossupressive drugs (7). Therefore, Pgp plays a very important role in drug disposition (absorption, distribution, and excretion processes) $(8,9)$. It is well known that Pgp is expressed constitutively at relatively high levels in many normal tissues such as intestinal epithelial cells, placenta, biliary canalicular cells, kidney, bloodbrain barrier and immune system cells such as lymphocytes (10-12). Regarding the wide tissue distribution and the effect on membrane transport of Pgp, the expression and activity of this protein could be essential in highlighting drug interactions.

Corresponding Author: Núria Lloberas, Nephrology Service, Hospital Universitari de Bellvitge, Lab Exp Nephrology 4122, Pab. Govern, $4^{\mathrm{a}}$ planta, UB, Feixa Llarga s/n, 08907 L'Hospitalet de Llobregat, Catalonia, Spain; Email: nlloberas@ub.edu

*Authors with equal contribution 


\section{ABBREVIATIONS}

Rhodamine123 (Rh123), P-glycoprotein (Pgp), ATP-Binding Cassette (ABC), Multidrug Resistance-1 (MDR-1), Annexin-V PE (AnnV), 7-Aminoactinomycin D (7-AAD), Binding Buffer (BB), Phosphate Buffered Saline (PBS), Foetal bovine serum (FBS), fresh non-frozen lymphocytes (F/NFr), fresh frozen lymphocytes $(\mathrm{F} / \mathrm{Fr})$, non-fresh non-frozen lymphocytes (NF/NFr), non-fresh frozen lymphocytes (NF/Fr), Mean fluorescence intensity (MFI), Verapamil (VP) and Flow analysis cell sorter (FACS).

Measuring the protein level of Pgp is not always an indicator of the efflux activity of the protein. The MDR-1 activity controlling Pgpdependent drug transport depends on two factors: 1) the level of expression of the MDR-1 gene that controls the amount of protein synthesized in the cells, where several single nucleotide polymorphisms in the MDR-1 gene have been identified, and 2) the functionality of the MDR-1encoded Pgp (13).

Several methods have been developed to measure Pgp activity in blood samples (14-19). In all of them lymphocyte isolation and incubation with substrates (such as Rh123) in the presence or absence of specific Pgp inhibitors followed by FACS analysis are performed. Some authors carry out Pgp activity assays using lymphocytes isolated from fresh blood, which could be a limitation. Despite some uncontrolled factors such as co-medication $(9,20)$, age $(21,22)$ and interindividual differences in Pgp activity considered for result analysis (23), some methodological factors ought to be taken into account. There are no data comparing Pgp activity measured from fresh lymphocytes with cryo-preserved lymphocytes. Furthermore, most authors do not specify under which conditions cells are preserved and stored before measuring Pgp activity. The published studies do not specify whether they use lymphocytes isolated from fresh drawn blood, lymphocytes isolated within the 24 hours after the drawing, frozen lymphocytes isolated from fresh drawn blood, or lymphocytes isolated from blood drawn and frozen within 24 hours of the extraction and then thawed prior the assays. In view of the fact that Pgp is a labile protein and its activity could be lost depending on the temperature, these methodological factors should be considered because they determine the interval of time among blood collection, lymphocyte isolation and Pgp activity assays.

Therefore, this present study aimed to compare Pgp expression and Rhodamine123 (Rh123) retention in lymphocytes stored under different conditions to evaluate the potential influence of any of the storing conditions on Pgp expression and functionality.

\section{MATERIALS AND METHODS}

\section{Drugs and Reagents}

The following drugs and reagents were used for the activity assays: Annexin-V PE (AnnV) (BD Pharmingen, CA, USA), 7-Aminoactinomycin D (7-AAD) (Sigma-Aldrich, Madrid, Spain), Binding Buffer (BB) (Medical and Biological Laboratories, Japan), Phosphate Buffered Saline (PBS) (PAA, Cambridge, UK), RPMI (Biological Industries, Israel), Rhodamine 123 (Molecular Probes Inc., USA), and PSC833 (kindly provided by Novartis, Basel, Switzerland). To select $\mathrm{T}$ lymphocytes from the whole lymphocyte population, CD3-APC conjugated Mouse antiHuman monoclonal antibody (BD Pharmingen, CA, USA) was used. To detect P-glycoprotein in lymphocytes by Western blot, the antibody C-219 was used (Calbiochem, Germany).

\section{Cell lines}

Two cell lines were used as a positive control for both the expression and the function of $\mathrm{P}$ glycoprotein. The cells lines used were SW1573/2R160, a Pgp-overexpressing cell line, and its counterpart SW1573 parental cell line. Both cell lines were cultured on DMEM supplemented with $10 \% \mathrm{FBS}, 1 \%$ L-Glutamine, and $1 \%$ penicillin-streptomycin (Biological Industries, Israel), at $37^{\circ} \mathrm{C}$ and $5 \% \quad \mathrm{CO}_{2}$ atmosphere. The overexpression of Pgp in the SW1573/2R160 cell line was maintained by adding $160 \mathrm{nM}$ of doxorubicin to the culture media every two to three passages. Both cell lines were a kind gift from Dr. G. Scheffer and Dr. R. Skepper of the Free University Medical Center, Amsterdam, The Netherlands.

\section{Human lymphocytes}

Informed consent was obtained from each healthy volunteer after the nature and possible consequences of the study were fully explained. 
Written informed consent was obtained from all healthy volunteers in accordance with the Hospital Universitari de Bellvitge Ethic Committee.

\section{Lymphocyte isolation}

Lymphocytes were obtained from fresh venous blood from healthy volunteers, collected into EDTA tubes and kept at room temperature, and separated by standard Ficoll-Paque (Amersham Biosciences, UK) gradient centrifugation. After isolation, $25 \times 10^{6}$ lymphocytes were frozen in freezing media lymphocyte consisting of RPMI, $20 \%$ DMSO and $20 \%$ FBS, $1: 1$, with FBS. Before activity assay, lymphocytes were rapidly thawed, washed twice with culture medium to free them of DMSO, and incubated for 2 hours at $37^{\circ} \mathrm{C}$ and $5 \%$ $\mathrm{CO}_{2}$ in culture medium (RPMI supplemented with $15 \%$ FBS and $1 \%$ L- Glutamine). In the nonfrozen group ( $\mathrm{F} / \mathrm{NFr}$ and $\mathrm{NF} / \mathrm{NFr}$ ), lymphocytes were incubated with culture medium for 2 hours before the assay.

Blood sampling was performed in healthy volunteers $(\mathrm{n}=12,6 \mathrm{men} / 6$ women) ranging from 23 to 53 years old. Four storage conditions of lymphocytes were used: fresh lymphocytes (F/NFr) $(n=12)$, lymphocytes frozen immediately after the extraction $(\mathrm{F} / \mathrm{Fr})(\mathrm{n}=12)$, lymphocytes isolated within 24 hours after the extraction $(\mathrm{NF} / \mathrm{NFr})(\mathrm{n}=12)$ and lymphocytes isolated within 24 hours after the extraction and immediately frozen $(\mathrm{NF} / \mathrm{Fr})(\mathrm{n}=12)$.

\section{P-glycoprotein expression: Western Blot}

Membrane protein extracts were obtained by homogenizing lymphocytes in 100-300 $\mu 1$ of lysis buffer (10mMTrisCl, $1.5 \mathrm{mMMgCl}_{2}, 10 \mathrm{mMKCl}$ and $0.5 \%$ SDS) containing $4 \%$ protease inhibitor cocktail (Roche, Switzerland) and 2\% PMSF. The extracts were stained on ice for 45 minutes and sonicated four times during that time. Then they were centrifuged for 10 minutes at $4^{\circ} \mathrm{C}$ at $400 \mathrm{~g}$, and the supernatant was recovered and ultracentrifuged for 1 hour at $4^{\circ} \mathrm{C}$ at $18,000 \mathrm{~g}$. The pellet was resuspended in $200 \mu 1$ of lysis buffer containing $4 \%$ protease inhibitor cocktail and $2 \%$ PMSF. Quantification of membrane proteins was done using the BCA Assay (Pierce, IL, USA), following the instructions of the manufacturer. $80 \mu \mathrm{g}$ of protein lysates were separated on to an $8 \%$ SDS-polyacrylamide gel and transferred to PVDF membranes (BioRad, CA, USA). The membranes were blocked in $5 \%\left(\mathrm{w} \mathrm{v}^{-1}\right)$ non-fat dry milk in Tris-buffered saline, $\mathrm{pH}$ 7.4, containing $0.1 \%$ Tween 20 (TBST) (50 mM Tris$\mathrm{HCl}, \mathrm{pH} 7.5,150 \mathrm{mM} \mathrm{NaCl}, 0.1 \%$ Tween-20) at room temperature for $1 \mathrm{~h}$. Blocked membranes were incubated with primary mouse antibodies specific to Pgp, C219 (1:100) (CalbiochemNovabiochem, San Diego, CA, U.S.A.) in TBST containing $5 \% \mathrm{BSA}$ at $4^{\circ} \mathrm{C}$ overnight as described previously (24). After incubation, immunoblots were washed with TBST and incubated at room temperature for $1 \mathrm{~h}$ with the horseradish peroxidase conjugated antimouse secondary antibody (1:5000, Dako, Denmark) in TBST containing 5\% milk. ECL detection kit (Pierce, IL, USA) was used to detect the protein bands. Pgp levels were expressed as a percentage of respective control groups. $\beta$-Actin (Cell Signaling Technology, Danvers, MA) was used as a comparator using antibody detection on stripped blots to confirm equal protein loading and blotting.

\section{P-glycoprotein mRNA level by quantitative real-time PCR (qRT-PCR)}

Total RNA was obtained following the Trizol manufacturer's instructions (Invitrogen, Carlsbad). The RNA used for the study had a $28 \mathrm{~s} / 18 \mathrm{~s}$ ratio between 1.8 and 2.0. Total RNA was reverse-transcribed as follows: $2 \mu \mathrm{g}$ of RNA was incubated with $1 \mu \mathrm{l}$ of $50 \mu \mathrm{M}$ random hexamers followed by RNA denaturalization. Then, $5 \mathrm{x}$ reaction buffer was added, $0.4 \mu 1$ of $100 \mathrm{mM}$ dNTP mix, and MMLV retrotranscriptase $200 \mathrm{u} / \mu 1$ (Ecogen, Langhorne, PA, USA) was added for a final volume of $20 \mu 1$. The reaction was incubated for $5 \mathrm{~min}$ at $25^{\circ} \mathrm{C}$, followed by $30 \mathrm{~min}$ at $42^{\circ} \mathrm{C}$ and $85^{\circ} \mathrm{C}$ for $5 \mathrm{~min}$ to stop the reaction. Real-time PCR was performed using $5 \mu 1$ of cDNA, primers and the TaqMan probe for MDR1 (Hs00184500_m1, Applied Biosystems, CA, USA), and the $\overline{A B I}$ Prism 7700 Sequence Detector. The level of target gene expression was determined using the $\Delta \Delta \mathrm{Ct}$ method as described previously (25), normalized to the GAPDH (Hs99999905_m1) control (Applied Biosystems, CA, USA). Results were expressed as many fold Pgp. Duplicates were carried out in each experiment.

\section{P-glycoprotein function in lymphocytes: Rh123 retention assay}

$500 \mu \mathrm{l}$ of the cell suspension $\left(10^{6}\right.$ cells/ tube) in serum-free RPMI was added to 3 test tubes: 1 tube, to evaluate cell auto-fluorescence: efflux 
control (EC); 1 tube, to evaluate Rh123 efflux (E0), and the last tube, to evaluate the effect of PSC833 on Rh123 efflux (EV). $400 \mu$ of Binding Buffer (BB) was added to the EC tube. PSC833 was added to the $\mathrm{EV}$ tube at a final concentration of $10 \mu \mathrm{M}$. Then, $2.1 \mu 1$ of Rh123 at $500 \mu \mathrm{M}$ $(0.525 \mu \mathrm{M}$ final $)$ dissolved in methanol was added to the E0 and EV tubes. All the tubes were incubated for $30 \mathrm{~min}$ at $37^{\circ} \mathrm{C}$, avoiding light exposure. At the end of incubation, the tubes were kept on ice a few minutes to stop Pgp efflux activity. Cells were centrifuged for $10 \mathrm{~min}$ at 450 $\mathrm{g}$ at $4^{\circ} \mathrm{C}$ and washed again with $2 \mathrm{ml}$ of BB. After washing, the cells were diluted in $50 \mu \mathrm{l}$ of $\mathrm{BB}$ containing $2 \mu 1$ of CD3-APC, except for the EC tube, and incubated on ice for $30 \mathrm{~min} .250 \mu \mathrm{l}$ of BB containing $2 \mu \mathrm{l}$ AnnV (to detect apoptotic cells) and $2 \mu \mathrm{l}$ of 7-AAD (to detect cells with membrane damage) were added in all tubes except the EC and incubated for $15 \mathrm{~min}$ on ice avoiding light exposure, prior to flow cytometry analysis. The samples were acquired on a FACSCalibur flow cytometer (Becton and Dikinson, BD) with four-color analysis. 10,000 CD3+ events were acquired and analyzed using CellProQuest software (BD). The instrument settings were established first and compensation was adjusted by acquiring cells stained with each fluorochrome. FSC and SSC were collected using linear scales and fluorescence signals were collected using logarithmic scales. All the data were collected in list mode. Results were expressed as the mean fluorescence intensity (MFI). Efflux activity was calculated as (MFI of Rh123 (FL1) (EV) - MFI of Rh123 (E0))/ $\left(\sqrt{s d}_{\mathrm{sd}^{2}}\right.$ $(\mathrm{EV})+\mathrm{sd}^{2}(\mathrm{EO})$ ), while retention ratio was calculated as (MFI of Rh123 (EV)/ MFI of Rh123 (EO)). Each experiment was performed three times.

The same protocol was performed with the first generation Pgp inhibitor Verapamil, using a range of different concentrations $(10$ to $50 \mu \mathrm{M})$ to establish the best functional and non-toxic concentration, at $20 \mu \mathrm{M}$ for lymphocytes and 40 $\mu \mathrm{M}$ for the SW1573 cell lines.

\section{Statistical Analysis}

Rh123 retention of the four conditions of lymphocytes was measured in $\mathrm{n}=12$ healthy volunteers. The activity was measured both in AnnV negative and 7-ADD negative population, and apoptotic (AnnV positive population) lymphocytes. Non-parametric statistical analysis was performed, using the non-parametric Mann-
Whitney test to compare the activity of $\mathrm{F} / \mathrm{Fr}$, $\mathrm{NF} / \mathrm{NFr}$ and NF/Fr CD3 + cells to the activity of $\mathrm{F} / \mathrm{NFr} \mathrm{CD} 3+$ lymphocytes. The analysis was performed both within the viable and the apoptotic lymphocytes, and also between viable and apoptotic lymphocytes.

\section{RESULTS}

\section{Pgp lymphocyte expression under four different storage conditions}

Western Blot. Pgp expression in lymphocytes was measured and compared in all storage conditions. The four conditions showed no differences in the protein levels (Fig 1). Pgp is a protein that is glycosylated in several positions, adopting different molecular weights, as can be seen in the overexpressing Pgp cell line SW1573/2R160 used as a positive control.

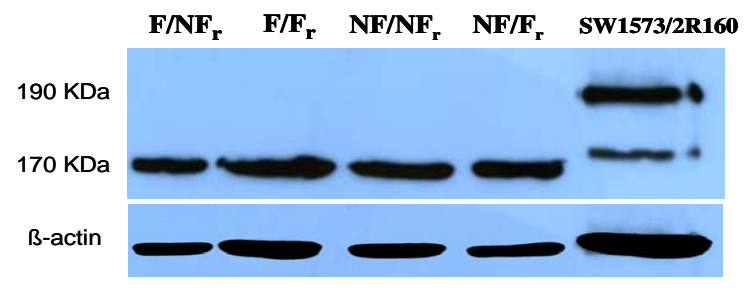

Figure 1. Pgp expression in $\mathrm{CD}^{+}$lymphocytes by Western blot analysis. Membrane protein extracts $(80 \mu \mathrm{g})$ from each of the lymphocyte conditions were separated in a SDS-polyacrylamide gel, and Pgp was detected with a specific antibody (C219). A positive cell line control that over-expresses Pgp was used (SW1573/2R160). All conditions showed a similar band in the $170 \mathrm{KDa}$ molecular weight. The different mobility observed in the positive control is due to different degrees of post-transductional modifications (glycosilation) of the protein.

Quantitative Real Time PCR. The expression of Pgp mRNA was measured to look for evidence of differences among the four storage conditions with the healthy volunteers. No statistical differences were found at the expression level of the transporter in the four conditions $(\mathrm{F} / \mathrm{NFr}=$ $1.0 \pm 0, \mathrm{~F} / \mathrm{Fr}=0.9 \pm 0.33, \mathrm{NF} / \mathrm{NFr}=0.74 \pm 0.12$ and $\mathrm{NF} / \mathrm{Fr}=0.68 \pm 0.51$ ), suggesting that freezing lymphocytes does not affect Pgp mRNA expression ( $p>0.05$ ) (Fig. 2). 


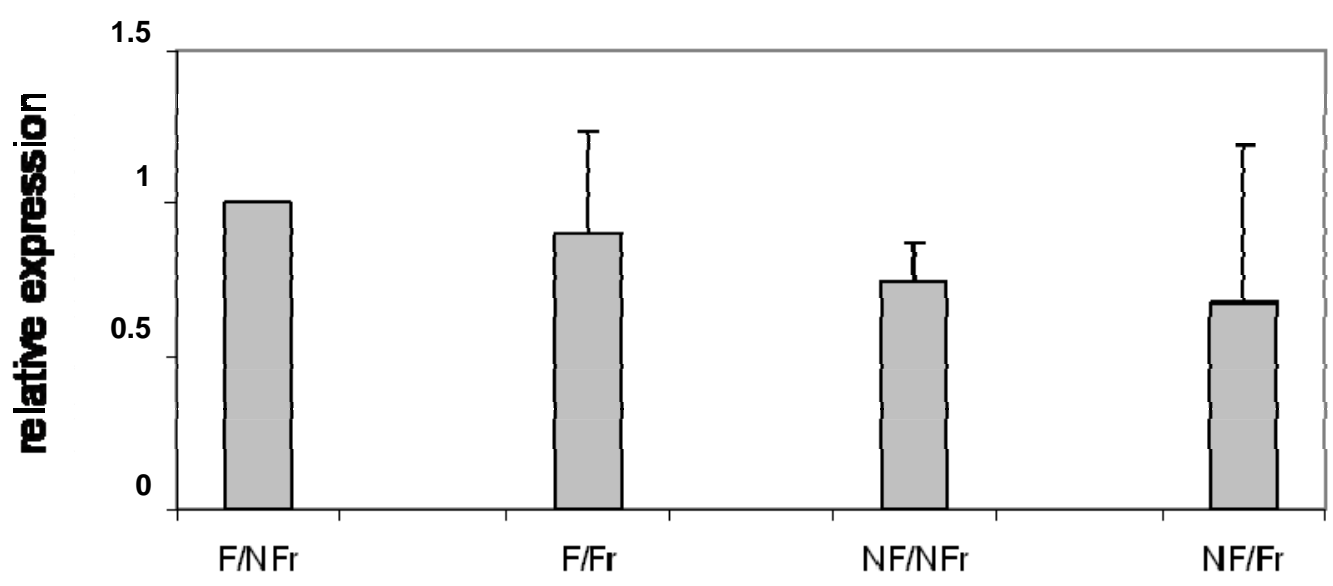

Figure 2. Pgp expression in $\mathrm{CD}^{+}$lymphocytes at the mRNA level by qRT-PCR. The expression of Pgp was measured by quantitative real-time PCR in the four conditions established in 12 healthy human volunteers. No significant differences were found related to F/NFr control group.

\section{Flow cytometry analysis of Rh123 retention in lymphocytes}

To assess which CD3+ lymphocytes were the optimal for studying Pgp activity, retention experiments using Rh123 were performed using viable $\mathrm{CD} 3+\mathrm{T}$ lymphocytes $\left(\mathrm{AnnV}^{-}\right.$and $\left.7 \mathrm{ADD}^{+}\right)$, excluding the early apoptotic $\left(\mathrm{AnnV}^{+}\right.$and $7 \mathrm{ADD}^{-}$ ), late apoptotic or necrotic $\left(\mathrm{AnnV}^{+}\right.$and $\left.7 \mathrm{ADD}^{+}\right)$ populations in different lymphocytes conditions. The four conditions of viable lymphocytes had a similar retention of Rh123 in the presence or absence of any of the inhibitors, showing a retention ratio of $2.05 \pm 0.10$ for VP and $1.36 \pm 0.07$ for PSC833 (Table 1) as an average value of the four conditions.

To assess whether freezing lymphocytes could modify Pgp activity, retention experiments in healthy volunteer lymphocytes were done. Rh123 retention in the CD3+ T viable cells was analyzed by FACS in the presence or absence of the inhibitors. Results were expressed in the four conditions by subtracting the mean channel of Rh123 MFI from the mean channel number of Rh123 MFI in the presence of VP or PSC833. As Figure 3 shows, the four conditions of lymphocyte demonstrated similar patterns of retention of $\mathrm{Rh} 123$ both in the absence and presence of the inhibitor. Pgp activity in the presence of the inhibitors in the four conditions resulted in an increase of approximately one logarithm of MFI compared with Rh123 alone. Therefore, no significant differences in Pgp activity were found. Results showed no inter- individual differences in $\mathrm{F} / \mathrm{NFr}$ vs $\mathrm{NF} / \mathrm{NFr}, \mathrm{F} / \mathrm{Fr}$ or $\mathrm{NF} / \mathrm{Fr}$ in $\mathrm{CD}^{+}$viable cells (Table 2). Additionally, we analyzed the differences of Pgp activity within the same individual in the four conditions in viable cells; no significant differences were found $(\mathrm{p}=0.183)$ (data not shown).

\section{Rh123 retention assay in viable versus early apoptotic lymphocytes}

Pgp activity in the early apoptotic $\mathrm{CD}^{+}$cell population $\left(\mathrm{AnnV}^{+} / 7-\mathrm{ADD}^{-}\right)$was not statistically different when comparing the four conditions $(\mathrm{F} / \mathrm{Fr} \quad(\mathrm{p}=0.66), \quad \mathrm{NF} / \mathrm{NFr}(\mathrm{p}=0.71)$ and $\mathrm{NF} / \mathrm{Fr}$ $(\mathrm{p}=0.87)$ ), taking the $\mathrm{F} / \mathrm{NFr}$ condition as a reference (Fig 4A). The Pgp activity observed in the apoptotic population was lower $(\mathrm{p}<0.05)$ than the activity in viable lymphocytes, probably due to the loss of functionality of the cell, and there was higher variability among different individuals compared to viable cells (Fig 4B). It should be mentioned that the apoptotic population represents a low percentage of the total $\mathrm{CD}^{+}$ lymphocytes $(4.5 \%)$. Therefore it was not considered in the Pgp activity analysis.

When measuring cell viability in the four conditions, $\mathrm{CD}^{+}$population was viable between $90 \%$ (F/NFr, NF/NFr) and $80 \%(\mathrm{~F} / \mathrm{Fr}, \mathrm{NF} / \mathrm{Fr})$. The early and late apoptotic and necrotic cells represented a minority of the lymphocyte population (Fig 5A). These results indicate that freezing lymphocytes partially modifies cell viability (Fig 5B). 
Table 1. Rh123 retention in the four conditions of viable CD ${ }^{+}$using two Pgp inhibitors: VP and PSC833.

\begin{tabular}{|c|c|c|c|c|c|c|}
\hline & VP((MFI) & Non VP(MFI) & $\begin{array}{c}\text { Retention } \\
\text { ratio }\end{array}$ & PSC833(MFI) & $\begin{array}{c}\text { Non PSC833 } \\
\text { (MFI) }\end{array}$ & $\begin{array}{c}\text { Retention } \\
\text { ratio }\end{array}$ \\
\hline F/NFr & $1232.09 \pm 117.40$ & $609.87 \pm 150.02$ & $2.02 \pm 0.06$ & $1576.37 \pm 117.47$ & $1237.76 \pm 91.37$ & $1.27 \pm 0.05$ \\
\hline F/Fr & $1629.97 \pm 164.18$ & $744.07 \pm 113.23$ & $2.19 \pm 0.11$ & $2279.03 \pm 146.67$ & $\begin{array}{c}1657.29 \pm 118.6 \\
4\end{array}$ & $1.34 \pm 0.07$ \\
\hline NF/NFr & $822.57 \pm 108.2$ & $408.18 \pm 78.56$ & $2.02 \pm 0.09$ & $1598.53 \pm 120.20$ & $1154.34 \pm 97.38$ & $1.38 \pm 0.06$ \\
\hline $\begin{array}{c}\mathrm{NF} / \mathrm{Fr} \\
\text { mean } \pm \text { sd }\end{array}$ & $1520.5 \pm 149.12$ & $777.19 \pm 95.48$ & $\begin{array}{l}1.96 \pm 0.12 \\
2.05 \pm 0.10\end{array}$ & $2262.00 \pm 120.77$ & $1574.07 \pm 98.65$ & $\begin{array}{l}1.43 \pm 0.09 \\
1.36 \pm 0.07\end{array}$ \\
\hline
\end{tabular}

MFI of Rh123 was measured after 30 min exposure in the presence and absence of the Pgp inhibitors VP and PSC833. When Pgp was blocked by VP, the four conditions of lymphocytes retained double the amount of Rh123 MFI without inhibitor (2.05 \pm 0.10 ); when using PSC833, the retention ratio was $1.36 \pm 0.07$. Results are expressed as the mean of MFI of Rh123 of 12 healthy volunteers. No significant differences in Rh123 retention were seen among the four conditions studied with the two inhibitors used ( $p=N S)$.

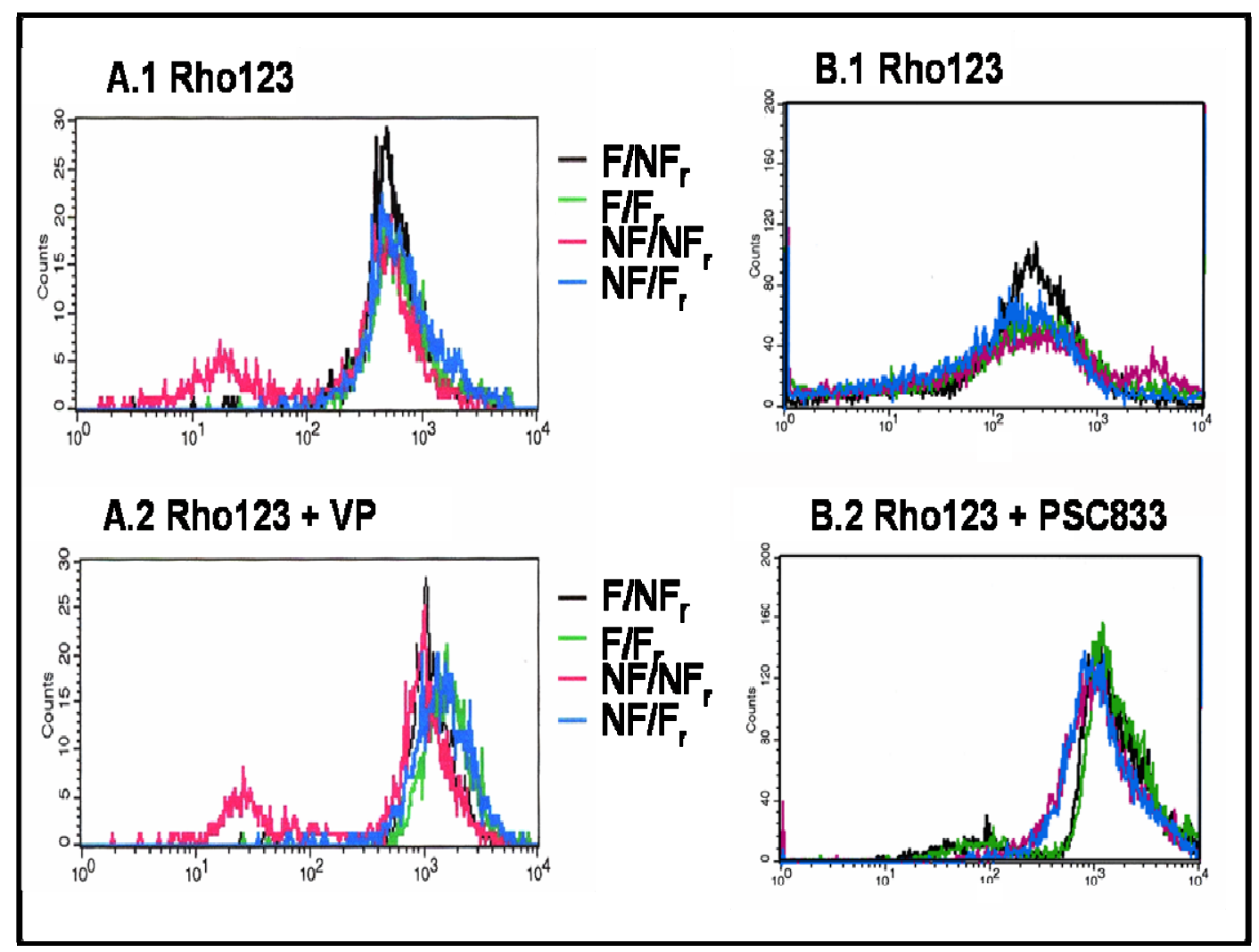

Figure 3. Pgp retention ratio of Rh123 in human lymphocytes measured by Flow cytometry analysis (FACs). Pgp retention ratio in the four conditions was measured in viable $\mathrm{CD}^{+}$lymphocytes (AnnexinV $/ 7 \mathrm{ADD}^{-}$) by $\mathrm{Rh}^{-} 23$ retention measurements detected by FACS. Retention was measured as mean fluorescence intensity (MFI) of Rh123 in a logarithmic scale. Retention of Rh123 by Pgp was estimated as a logarithm increase of MFI of Rh123 when a Pgp inhibitor is added. A.1 The Pgp retention of the Rh123 plot of the four conditions overlapped, meaning that Pgp activity was not modified due to the storing and sample manipulation. A.2. When VP was used to block Pgp, an increase in one logarithm of MFI of Rh123 was observed in all four conditions where the plots also overlapped. B.1 and B.2. The same results were observed when PSC 833 was used to inhibit Pgp activity. 

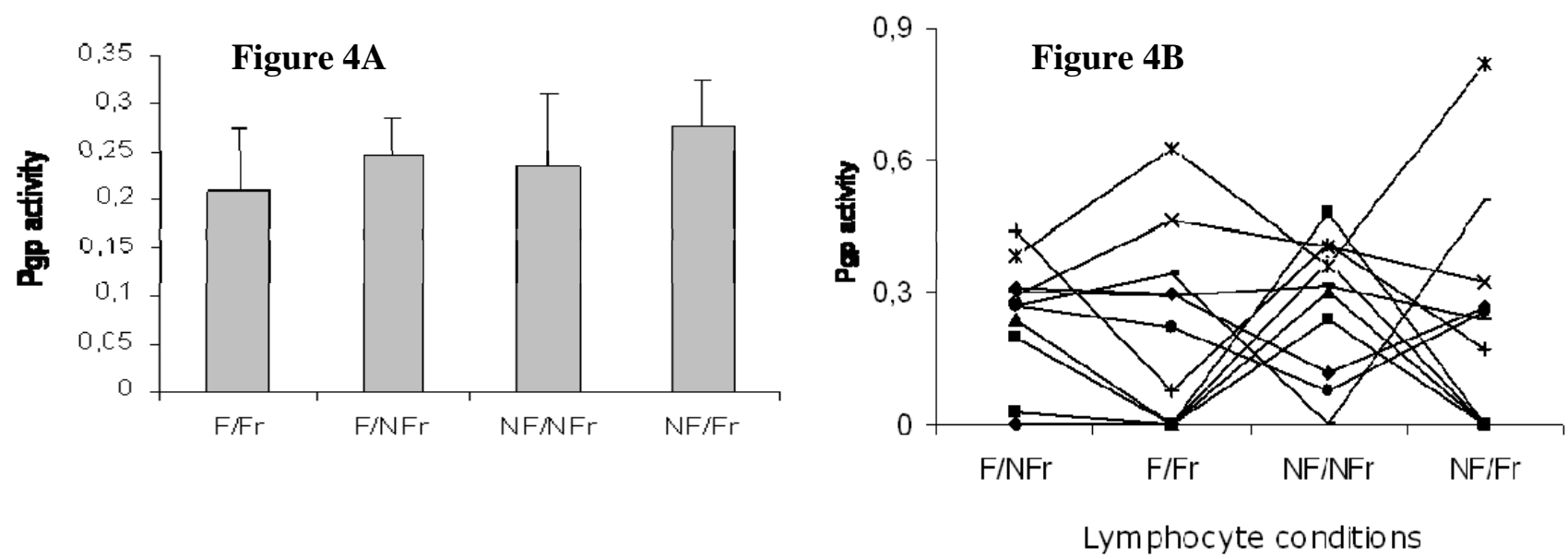

Figure 4. Pgp activity in apoptotic lymphocytes. Pgp activity was measured in the T cells' early apoptotic population $\left(\mathrm{CD}^{+} / \mathrm{AnnV}^{+} / 7-\mathrm{ADD}^{-}\right)$by Rh123 retention assays. A. Mean $(\mathrm{n}=12)$ of the activity measured in the four conditions of apoptotic lymphocytes. B. High variability was found in the activity measured within intra-individuals comparing the four conditions.

Table 2. Effect of storage conditions in the Pgp activity in $\mathrm{CD}^{+}$viable cells.

\begin{tabular}{ccc}
\hline & VP & PSC833 \\
\hline F/NFr & $0.121 \pm 0.061$ & $0.247 \pm 0.138$ \\
F/Fr & $0.184 \pm 0.071$ & $0.326 \pm 0.136$ \\
NF/NFr & $0.134 \pm 0.058$ & $0.331 \pm 0.097$ \\
NF/Fr & $0.215 \pm 0.095$ & $0.337 \pm 0.202$ \\
$\mathbf{p}$ & NS & NS \\
\hline
\end{tabular}

Pgp activity, calculated as (MFI of Rh123 in the presence of inhibitor (EV) - MFI of Rh123 in the absence of inhibitor (E0)) $/\left(\sqrt{ } \mathrm{sd}^{2}(\mathrm{EV})+\mathrm{sd}^{2}(\mathrm{EO})\right)$, was expressed as mean \pm sd of 12 healthy volunteers $(p=$ NS).

\section{DISCUSSION}

In this study, the expression of Pgp and Rh123 retention in lymphocytes handled and stored under four different conditions was measured, and our results showed no significant differences among the storage conditions. To date, studies by other groups have not specified the processing and storing conditions of the cells before analysis. Some groups performed Rh123 retention assays directly from fresh whole blood (26), and others from fresh isolated lymphocytes (27), but the majority of the studies have not indicated whether the lymphocytes were isolated from freshly drawn blood or blood stored at room temperature for a short period of time (28). The main interest of the present study is to show that Pgp expression and activity measured through Rh123 retention are not modified when blood is kept at room temperature for 24 hours nor when the lymphocyte isolation is carried out immediately after the blood is drawn.

Peripheral mononuclear cells are known to express $\mathrm{ABC}$ efflux transporters. Hence, isolated cells could be useful to study drugtransporters in the in vivo/ex vivo monitoring of the potential effects of drugs on the expression and activity of these transporters. There is clear evidence that normal blood cells, particularly natural killer (NK) cells and $\mathrm{T}$ lymphocytes, express Pgp (29), although the level of Pgp expression on lymphocytes does not imply a direct correlation with Pgp activity (30). This lack of correlation between Pgp expression and activity may be explained, in part, by the fact that functional analysis based on Pgp substrate dyes such as Rh123 is much more sensitive in the detection of low-level multidrug resistance than Pgp expression analysis $(31,32)$. Although NK cells play an important role in Pgp expression and function, this subpopulation represents a low percentage of the PBMC population. Therefore, considering that the $\mathrm{CD} 3+$ cells represent a high percentage of the PBMC, as they show functional Pgp expression and play a predominant role in immune response, this population was the most suitable for the purpose of the present study.

It has to be considered that Pgp is a fragile protein and could be inactivated by freeze/thawing cycles (33). Therefore manipulation of lymphocytes could be extremely critical in this regard. 

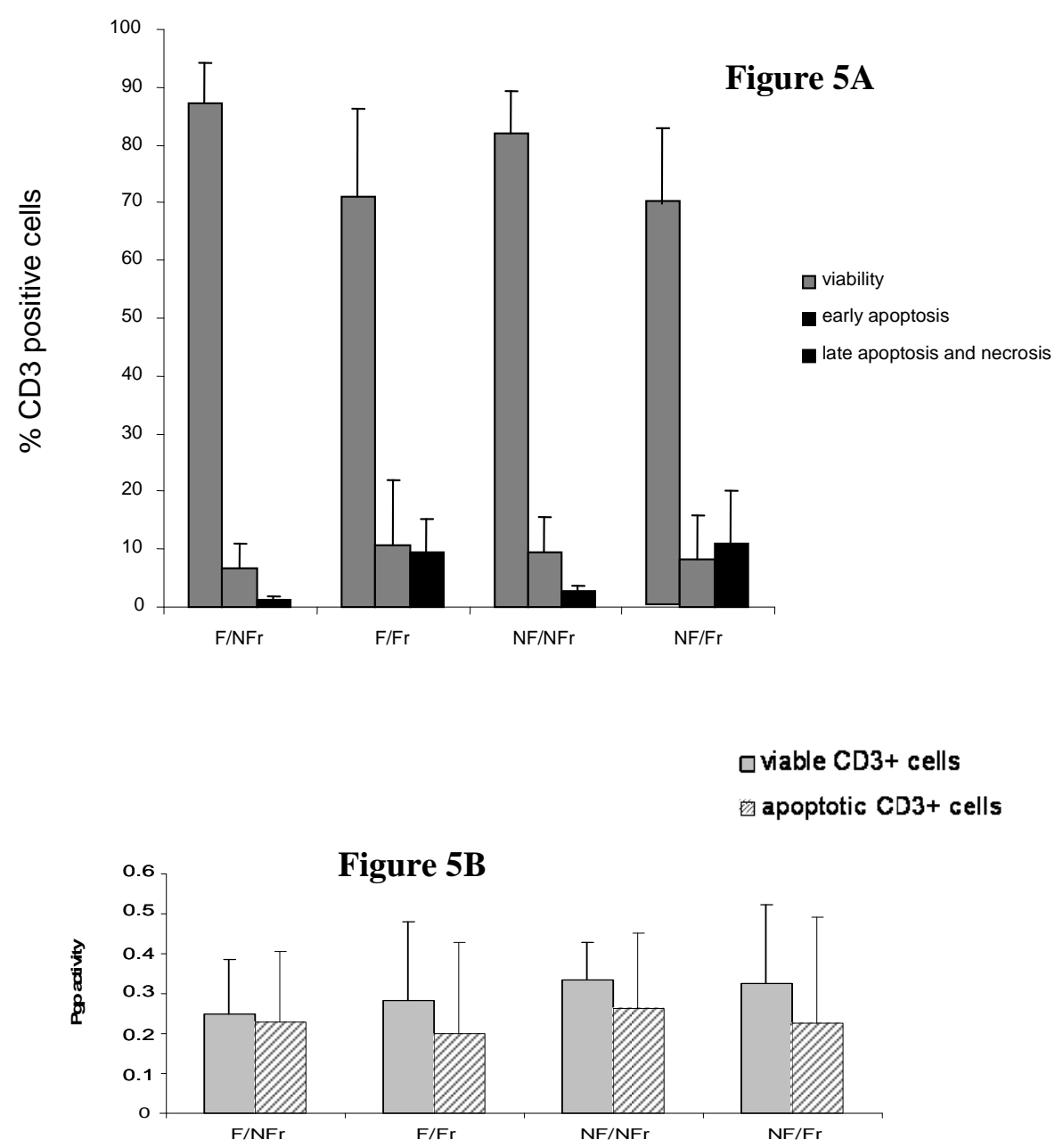

Figure 5. Cell viability in the four conditions of lymphocytes. A. In each lymphocyte condition cell viability was measured, distinguishing among viable $\left(\mathrm{CD}^{+} / \mathrm{AnnV}^{-} / 7-\mathrm{ADD}^{-}\right)$, early apoptotic $\left(\mathrm{CD}^{+} / \mathrm{AnnV}^{+} / 7-\mathrm{ADD}^{-}\right)$, late apoptotic and necrotic $\left(\mathrm{CD3}^{+} / \mathrm{AnnV}^{+} / 7-\mathrm{ADD}^{+}\right)$cells. In all four conditions viable cells were the vast majority. B. Pgp activity in viable and apoptotic $\mathrm{CD}^{+}$lymphocytes.

The manner of drawing, isolating and storing lymphocytes is a relevant key toward obtaining good reproducibility for the Pgp activity studies. For multicentre studies, where blood is collected from different centers and Pgp substrate retention assays have to be performed from lymphocytes isolated and/or stored under different conditions, it is critical to guarantee uniformity of the procedure conditions for all the samples. In the present study, lymphocytes were frozen and no significant changes in the expression or the activity of the Pgp protein were found.

One approach to measuring Pgp activity was the retention of Rh123 within the cells, in the presence and absence of Pgp inhibitors. The two efflux pump inhibitors used were the $\mathrm{Ca}^{+2}$ channel blocker VP and PSC833, a Pgp selective inhibitor, also known as Valspodar. The two inhibitors showed no differences in the Rh123 retention among the four conditions of the lymphocytes studied. Nevertheless, PSC833 is a more specific and potent inhibitor of Pgp than VP, as the concentration used to inhibit Ppg efflux was half the concentration of VP.

Within the $\mathrm{CD}^{+}$population, three cell subsets were compared in terms of Pgp efflux activity calculated by Rh123 retention measurements: viable, early apoptotic and late apoptotic lymphocytes. Although early apoptotic lymphocytes prove Pgp efflux activity, this population represents only $4.5 \%$ of the total lymphocytes purified from the blood samples. 
Therefore, not measuring the activity of the early apoptotic lymphocytes does not alter the results of activity obtained from viable population. In contrast, late apoptotic and necrotic cells should be considered separately or excluded because they always show background activity that interferes in the analysis of the viable lymphocyte Rh123 retention measurements. We established that in order to obtain the most accurate results, the apoptotic population should be considered separately and necrotic cells should be excluded.

\section{CONCLUSIONS}

Our results show that for the 24 hours post blood extraction, Pgp activity measured by Rh123 retention was not affected by the 4 different handling processes. They also confirm that in order to assess global Pgp activity, Pgp should be analyzed in viable cells, removing the necrotic population. These parameters could contribute to improve Pgp activity studies in individuals with different blood sampling timing and/or different geographic areas.

\section{ACKNOWLEDGEMENTS}

We thank all the healthy volunteers who contributed to the study. We also thank Novartis for kindly providing PSC833. This study was supported by Roche Foundation and grants from Instituto de Salud Carlos III (CP06/00067) and the Ministerio de Sanidad y Consumo (FIS PI070768; FIS 08/1085; ISCIII-RETIC RD06/0020/0097).

\section{REFERENCES}

1. Callaghan R, Crowley E, Potter S and Kerr ID. P-glycoprotein: so many ways to turn it on. J Clin Pharmacol, 48(3):365-378, 2008.

2. Bebawy $M$ and Sze DM. Targeting Pglycoprotein for effective oral anti-cancer chemotherapeutics. Curr Cancer Drug Targets, 8(1):47-52, 2008.

3. Li X, Li JP, Yuan HY, Gao X, Qu XJ, Xu WF and Tang $W$. Recent advances in Pglycoprotein-mediated multidrug resistance reversal mechanisms. Methods Find Exp Clin Pharmacol, 29(9):607-617, 2007.

4. Pendse SS, Behjati S, Schatton T, Izawa A, Sayegh MH and Frank MH. P-glycoprotein functions as a differentiation switch in antigen presenting cell maturation. Am J Transplant, 6(12):2884-2893, 2006.

5. van de Ven R, de Jong MC, Reurs AW, Schoonderwoerd AJ, Jansen G, Hooijberg JH,
Scheffer GL, de Gruijl TD and Scheper RJ. Dendritic cells require multidrug resistance protein 1 (ABCC1) transporter activity for differentiation. J Immunol, 176(9):5191-5198, 2006.

6. Fromm MF. Importance of P-glycoprotein at blood-tissue barriers. Trends Pharmacol Sci, 25(8):423-429, 2004.

7. Sun J, He ZG, Cheng G, Wang SJ, Hao XH and Zou MJ. Multidrug resistance $\mathrm{P}$ glycoprotein: crucial significance in drug disposition and interaction. Med Sci Monit, 10(1):RA5-14, 2004.

8. Ambudkar SV, Kim IW and Sauna ZE. The power of the pump: mechanisms of action of P-glycoprotein (ABCB1). Eur J Pharm Sci, 27(5):392-400, 2006.

9. Evans WE and McLeod HL. Pharmacogenomics--drug disposition, drug targets, and side effects. $\mathrm{N}$ Engl J Med, 348(6):538-549, 2003.

10. Gottesman MM and Ling V. The molecular basis of multidrug resistance in cancer: the early years of P-glycoprotein research. FEBS Lett, 580(4):998-1009, 2006.

11. Tazzari PL, Cappellini A, Ricci F, Evangelisti C, Papa V, Grafone T, Martinelli G, Conte R, Cocco L, McCubrey JA and Martelli AM. Multidrug resistance-associated protein 1 expression is under the control of the phosphoinositide 3 kinase/Akt signal transduction network in human acute myelogenous leukemia blasts. Leukemia, 21(3):427-438, 2007.

12. Leith CP, Chen IM, Kopecky KJ, Appelbaum FR, Head DR, Godwin JE, Weick JK and Willman CL. Correlation of multidrug resistance (MDR1) protein expression with functional dye/drug efflux in acute myeloid leukemia by multiparameter flow cytometry: identification of discordant MDR-/efflux+ and MDR1+/efflux- cases. Blood, 86(6):23292342, 1995.

13. Hoffmeyer S, Burk O, von Richter O, Arnold HP, Brockmoller J, Johne A, Cascorbi I, Gerloff T, Roots I, Eichelbaum $M$ and Brinkmann U. Functional polymorphisms of the human multidrug-resistance gene: multiple sequence variations and correlation of one allele with P-glycoprotein expression and activity in vivo. Proc Natl Acad Sci U S A, 97(7):3473-3478, 2000.

14. Petriz J, Gottesman MM and Aran JM. An MDR-EGFP gene fusion allows for direct cellular localization, function and stability assessment of P-glycoprotein. Curr Drug Deliv, 1(1):43-56, 2004.

15. Huet S, Marie JP, Gualde N and Robert J. Reference method for detection of Pgp mediated multidrug resistance in human hematological malignancies: a method 
validated by the laboratories of the French Drug Resistance Network. Cytometry, 34(6):248-256, 1998.

16. Oselin K, Gerloff T, Mrozikiewicz PM, Pahkla R and Roots I. MDR1 polymorphisms G2677T in exon 21 and C3435T in exon 26 fail to affect rhodamine 123 efflux in peripheral blood lymphocytes. Fundam Clin Pharmacol, 17(4):463-469, 2003.

17. Henmi K, Yoshida $\mathrm{M}$, Yoshikawa $\mathrm{N}$ and Hirano T. P-glycoprotein functions in peripheral-blood CD4(+) cells of patients with systemic lupus erythematosus. Biol Pharm Bull, 31(5):873-878, 2008

18. Chiarini F, Del Sole M, Mongiorgi S, Gaboardi GC, Cappellini A, Mantovani I, Follo MY, McCubrey JA and Martelli AM. The novel Akt inhibitor, perifosine, induces caspase-dependent apoptosis and downregulates P-glycoprotein expression in multidrug-resistant human T-acute leukemia cells by a JNK-dependent mechanism. Leukemia, 22(6):1106-1116, 2008.

19. Poulain S, Lepelley P, Cambier N, Wattel E, Fenaux $\mathrm{P}$ and Cosson A. Assessment of $\mathrm{P}$ glycoprotein expression by immunocytochemistry and flow cytometry coupled with functional efflux analysis: application to acute myeloid leukemia. Ann Biol Clin (Paris), 57(5):595-600, 1999.

20. Hitzl M, Drescher S, van der Kuip $H$, Schaffeler E, Fischer J, Schwab M, Eichelbaum M and Fromm MF. The C3435T mutation in the human MDR1 gene is associated with altered efflux of the Pglycoprotein substrate rhodamine 123 from CD56+ natural killer cells. Pharmacogenetics, 11(4):293-298, 2001.

21. Aszalos A. Drug-drug interactions affected by the transporter protein, P-glycoprotein (ABCB1, MDR1) II. Clinical aspects. Drug Discov Today, 12(19-20):838-843, 2007.

22. Brenner SS and Klotz U. P-glycoprotein function in the elderly. Eur J Clin Pharmacol, 60(2):97-102, 2004.

23. Pilarski LM, Paine D, McElhaney JE, Cass $\mathrm{CE}$ and Belch AR. Multidrug transporter Pglycoprotein 170 as a differentiation antigen on normal human lymphocytes and thymocytes: modulation with differentiation stage and during aging. Am J Hematol, 49(4):323-335, 1995.

24. Lloberas N, Torras J, Alperovich G, Cruzado JM, Gimenez-Bonafe P, Herrero-Fresneda I,
Franquesa ML, Rama I and Grinyo JM. Different renal toxicity profiles in the association of cyclosporine and tacrolimus with sirolimus in rats. Nephrol Dial Transplant, 23(10):3111-9, 2008.

25. Lee TB, Park JH, Min YD, Kim KJ and Choi $\mathrm{CH}$. Epigenetic mechanisms involved in differential MDR1 mRNA expression between gastric and colon cancer cell lines and rationales for clinical chemotherapy. BMC Gastroenterol, 8:33, 2008.

26. Robey R, Bakke S, Stein W, Meadows B, Litman T, Patil S, Smith T, Fojo T and Bates $\mathrm{S}$. Efflux of rhodamine from CD56+ cells as a surrogate marker for reversal of Pglycoprotein-mediated drug efflux by PSC 833. Blood, 93(1):306-314, 1999.

27. Lamy $\mathrm{T}$, Drenou $\mathrm{B}$, Fardel $\mathrm{O}$, Amiot L, Grulois I, Le Prise PY, Loughran TP, Jr. and Fauchet R. Multidrug resistance analysis in lymphoproliferative disease of large granular lymphocytes. Br J Haematol, 100(3):509-515, 1998.

28. Benderra Z, Faussat AM, Sayada L, Perrot JY, Tang R, Chaoui D, Morjani H, Marzac C, Marie JP and Legrand O. MRP3, BCRP, and $\mathrm{P}$-glycoprotein activities are prognostic factors in adult acute myeloid leukemia. Clin Cancer Res, 11(21):7764-7772, 2005.

29. Park SW, Lomri N, Simeoni LA, Fruehauf JP and Mechetner E. Analysis of P-glycoproteinmediated membrane transport in human peripheral blood lymphocytes using the UIC2 shift assay. Cytometry A, 53(2):67-78, 2003.

30. Vasquez EM, Petrenko Y, Jacobssen V, Sifontis NM, Testa G, Sankary $H$ and Benedetti E. An assessment of P-glycoprotein expression and activity in peripheral blood lymphocytes of transplant candidates. Transplant Proc, 37(1):175-177, 2005.

31. Webb M, Raphael CL, Asbahr H, Erber WN, Meyer BF. The detection of rhodamine 123 efflux at low levels of drug resistance. $\mathrm{Br} \mathrm{J}$ Haematol, 93(3):650-655, 1996.

32. Delaney MP, Smythe E, Higgins RM and Morris AG. Constitutive and acquired resistance to calcineurin inhibitors in renal transplantation: role of P-glycoprotein-170. Transpl Int, 13(4):276-284, 2000.

33. Ambudkar SV, Lelong IH, Zhang $\mathrm{J}$ and Cardarelli C. Purification and reconstitution of human P-glycoprotein. Methods Enzymol, 292:492-504, 1998. 